\title{
Effect of aluminum closed-cell foam filling on the quasi-static axial crush performance of glass fiber reinforced polyester composite and aluminum/composite hybrid tubes
}

\author{
M. Guden*, S. Yüksel, A. Taşdemirci, M. Tanoğlu \\ Department of Mechanical Engineering, Izmir Institute of Technology, Gülbahçe Köyü, Urla, 35430 Izmir, Turkey
}

Available online 30 October 2006

\begin{abstract}
The effect of Al closed-cell foam filling on the quasi-static crushing behavior of an E-glass woven fabric polyester composite tube and thin-walled $\mathrm{Al}$ /polyester composite hybrid tube was experimentally investigated. For comparison, empty Al, empty composite and empty hybrid tubes were also tested. Empty composite and empty hybrid tubes crushed predominantly in progressive crushing mode, without applying any triggering mechanism. Foam filling was found to be ineffective in increasing the crushing loads of the composite tubes over the sum of the crushing loads of empty composite tube and foam. However, foam filling stabilized the composite progressive crushing mode. In empty hybrid tubes, the deformation mode of the inner Al tube was found to be a more complex form of the diamond mode of deformation of empty Al tube, leading to higher crushing load values than the sum of the crushing load values of empty composite tube and empty metal tube. The foam filling of hybrid tubes however resulted in axial splitting of the outer composite tube due to the resistance imposed by the foam filler to Al tube inward folding and hence it was ineffective in increasing crushing load and SAE values over those of empty hybrid tubes.
\end{abstract}

(C) 2006 Elsevier Ltd. All rights reserved.

Keywords: Axial crush resistance; Aluminum foam; Composite tube; Hybrid tube; Energy absorption

\section{Introduction}

The light-weight foam filling of metallic columnar structures increases the Specific Absorbed Energy (SAE) values of foam-filled tubes over those of empty counterparts when appropriate tube geometry, tube wall-foam filler bonding and foam density are chosen [1-3]. The earliest investigations on the crushing behavior of foam-filled thin-walled metallic sections are found in [4-7] and the most recent studies in $[2,8-10]$. Foam filling usually results in an interaction between tube wall and foam filler, increasing the average crushing loads of filled tube over the sum of the crushing loads of foam (alone) and tube (alone). The encroachment of the tube wall into the foam filler was suggested to allow an additional compression in the filler, retarding the sectional collapse of the tube [9]. Asymmetric

\footnotetext{
* Corresponding author. Tel.: +90 232 7507816; fax: +90 2327507890.

E-mail address: mustafaguden@iyte.edu.tr (M. Guden).
}

(diamond) and axisymmetric (concertina) folding are the two competing progressive metal tube crushing modes. Thick isotropic metal tubes generally collapse by concertina, whereas thin-walled metal tubes collapse by diamond mode of folding. It was further shown in Al closed-cell foam-filled $\mathrm{Al}$ and steel tubes, polyurethane foam-filled Al tubes and wood sawdust-filled plastic tubes $[8,9,11,12]$ that foam filling increased the tendency for concertina mode of folding.

Ramakrishna [13] studied the effects of material property and geometric and testing variables on the energy absorption capabilities of various types of polymer matrix composite tubes. The energy absorption in composite tubes varied significantly depending on fiber and matrix type, fiber-matrix interface bonding, fiber content and architecture and environmental conditions. It was shown in the same study that short circular composite tubes crush under compressive loads mainly in two different modes: catastrophic (brittle) and progressive crushing. Compression 
shear resulting from fiber micro-buckling and axial splitting generally leads to the catastrophic failure of composite tubes $[13,14]$. The catastrophic failure mode is characterized by an abrupt decrease in crushing loads following the initial peak-load. On the other hand, progressive crushing mode proceeds with fragmentation, splaying and folding modes [15] and results in very high levels of energy absorption associated with the large number of micro fractures that occur as the tube crushes. The effect of splaying direction (internal and external) on the static and dynamic crushing load values of a composite tube was previously investigated [16]. It was shown that internal splaying absorbed more energy than external splaying in static tests. Chiu et al. [17] investigated progressive crushing of biaxially and triaxially braided composite tubes. The average width of splaying fronds increased with increasing braiding angle but decreased with increasing axial yarn content. Turner et al. [18] showed that the SAE levels of random mat and non-clip continuous E-glass fiber fabric reinforced polyester composite tubes were slightly affected by the matrix void volume content up to $10 \%$, which could allow the rapid and cost effective processing of composite tubes for crush applications. Worrior et al. [19] showed that an equilibrium between in-plane and through thickness properties of an E-glass fiber reinforced composite tube existed for high energy absorption levels. The effects of resin type and resin properties on the crushing performance of glass fiber reinforced epoxy, polyester and vinyl ester composites were also studied for comparison [20]. The epoxy matrix composite tubes were shown to absorb more SAE than vinyl ester and polyester composite tubes. Zeng et al. [21] modeled the effects tube inner radius, tube thickness and braid angle on the dynamic SAE values of a 3-D braided (carbon fiber)/epoxy composite tube and found well agreements between the numerical predictions and experimental results. It was shown that as the tube inner radius to thickness ratio increased the buckling became the dominant crushing mode and hence SAE values decreased. It was also shown in the same study that braiding angle affected greatly the SAE values of the tube.

Despite the many experimental investigations conducted to understand the crushing behavior of foam-filled metal and empty composite tubes, the crushing behavior of empty and foam-filled hybrid (metal/composite tube) and foam-filled composite tubes have not been investigated as much. Shin et al. [22] investigated the axial crushing and energy absorption behavior of an $\mathrm{Al} /$ glass fiber reinforced epoxy square composite hybrid tube through ply orientations of $0^{\circ}, 90^{\circ}, 0^{\circ} / 90^{\circ}$ and $\pm 45^{\circ}$. In $90^{\circ}$ ply orientation the hybrid tube showed the highest SAE. Without any triggering mechanism, the failure mode in $90^{\circ}$ ply orientation was stable and progressive, while it was catastrophic failure mode in $0^{\circ}$ and mixed mode in $0^{\circ} / 90^{\circ}$ and $\pm 45^{\circ}$ ply orientation. Harte et al. [23] investigated the compression and tensional behavior of braided glass fiber/epoxy circular tubes with and without polymer foam fillers. The energy absorption values of tubes deforming in concertina mode were found to increase with foam filling. Babbage and Mallick [24] investigated the static axial crushing behavior of empty and epoxy foam-filled Al/filament-wound E-glass fiber reinforced epoxy composite tubes. The composite overwrap increased the peak-load, average crushing load and SAE values of Al square and circular tubes. Epoxy foam filling of round $\mathrm{Al} /$ composite hybrid tubes further improved the axial crush performance of the empty circular hybrid tubes, while foam filling of square hybrid tubes resulted in the failure of $\mathrm{Al}$ tube either via buckling or tearing at the corners due to the prevention of tube inward folding by the foam filler.

The main objective of this experimental study is to determine the effect of foam filling on the crushing load and SAE values of composite and hybrid (metal/composite) tubes. The static compression tests were therefore conducted on small size tube samples with and without closedcell $\mathrm{Al}$ foam filling and the associated crushing behaviors were compared with those of empty hybrid, empty composite and empty $\mathrm{Al}$ tubes in order to assess the advantages of foam filling and the use of hybrid tube construction.

\section{Materials and experimental methods}

E-glass fiber woven fabric/polyester composite tubes were prepared in house by hand-rolling of the pre-wetted woven-fabrics onto a surface-polished $25 \mathrm{~mm}$ steel bar. The reinforcing E-glass woven fabric, comprising $2 \times 2$ twill $\left(0^{\circ} / 90^{\circ}\right)$ fiber construction (Fig. 1), had an areal density of $165 \mathrm{~g} \mathrm{~m}^{-2}$. The polymer matrix was prepared by mixing iso-polyester resin (blend of isophatalic acid and maleic anhydride or fumaric acid), with $1.5 \mathrm{wt} \%$ hardener solution containing $5 \mathrm{wt} \%$ Mek-peroxide and $0.28 \mathrm{wt} \%$ curing agent solution containing $6 \mathrm{wt} \%$ cobalt octoat. Initially, the fabric was cut into rectangular sections and then impregnated by the resin. The impregnated cut-fabric sections were then rolled on the steel bar. Before the rolling

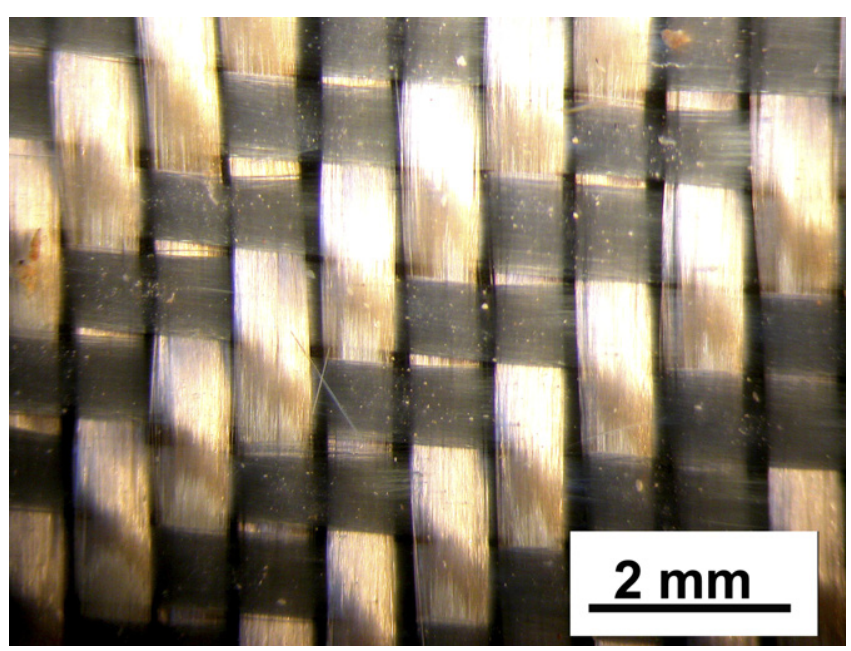

Fig. 1. E-glass woven fabric with $2 \times 2$ twill $\left(0^{\circ} / 90^{\circ}\right)$ construction. 
of the fabric, a mold-releasing agent was uniformly spread out on the bar surface for easy-removal of the cured tube. Following the initial curing stage at room temperature, the composite tube was post-cured in a furnace at $120^{\circ} \mathrm{C}$ for $2 \mathrm{~h}$. After post curing, the tube was de-molded and finally sectioned into $27 \mathrm{~mm}$ long compression test samples using a slow-speed diamond saw. Empty tubes with fiber orientations $\pm 45^{\circ}$ in the tube long axis were initially prepared in varying wall thicknesses and tested in order to determine the effect of wall thickness on the crushing behavior. The thicknesses of the tubes were determined by the number of the fabric layer used; 3-layer fabric ended up with a wall thickness of approximately $0.6 \mathrm{~mm}$, 5-layer $0.8 \mathrm{~mm}$ and 7 layer $1.30 \mathrm{~mm}$ (Fig. 2(a)-(c)). In order to determine the effect of foam filling on the composite tube crushing behavior, the composite tubes with wall thicknesses of 0.56 $0.65 \mathrm{~mm}$ were filled with closed-cell $\mathrm{Al}$ foams of varying densities, ranging between 0.25 and $0.61 \mathrm{~g} \mathrm{~cm}^{-3}$. The top view of a foam-filled composite tube is shown in Fig. 2(d). Al closed-cell foams were prepared in house using the foaming from powder compacts process patented by Fraunhofer Resource Center of Germany [25]. In this process, dense $\mathrm{Al}$ powder compacts containing $\mathrm{TiH}_{2}$ blowing agent were heated above the melting temperature of $\mathrm{Al}$, $750{ }^{\circ} \mathrm{C}$. The foaming was conducted inside a square mold having $80 \mathrm{~mm}$ width and $40 \mathrm{~mm}$ height. Detailed information on the foam preparation method and compression mechanical behavior of the prepared $\mathrm{Al}$ foams is given in another study [26]. The thicknesses of prepared foam plates were machined down to $27 \mathrm{~mm}$ in order to remove the dense metal skin layer. Cylindrical $\mathrm{Al}$ foam cores were cut by electrical discharge machine with close tolerances through the thickness direction of foam plates; the long axis of cylinder was normal to the foam expansion direction.

Deep-drawn thin $\mathrm{Al}$ tubes $(99.7 \% \mathrm{Al})$ used to construct hybrid tubes were produced by METALUM Company of Turkey and received in $25 \mathrm{~mm}$ diameter with $0.29 \mathrm{~mm}$ wall thickness. The yield and ultimate strength of the tube material were previously determined at a quasi-static strain rate of $\sim 1 \times 10^{-3} \mathrm{~s}^{-1}$ [27]. Tubes were machined to $27 \mathrm{~mm}$ in length using a diamond saw. Before the insertion of the Al tubes and foam fillers inside the composite tubes, the surfaces of the Al tubes and foam fillers were cleaned with acetone. The top views of empty and foam-filled hybrid tubes are shown in Fig. 3(a) and (b), respectively. The foam


Fig. 3. (a) Empty and (b) foam-filled hybrid tubes.

density in foam-filled hybrid tubes was $0.4 \mathrm{~g} \mathrm{~cm}^{-3}$. Since the diameter of the foam fillers was the same as the inner diameter of the tubes, the foam fillers fitted tightly inside the composite and hybrid tubes without imposing any external pressure. A thin layer of polyester resin was used as the bonding agent between the filler and tubes surfaces. The weights and dimensions of tubes and fillers were measured before and after the filling. The weight of the adhesive used was calculated and found to vary between $3 \%$ and $6 \%$ of the total weight of the filled tubes.

Quasi-static compression tests on empty and foam-filled tubes and foam samples were conducted in a displacement controlled SHIMADZU AG-I universal testing machine with a displacement rate of $2 \mathrm{~mm} \mathrm{~s}^{-1}$, using an eccentric compression upper test platen. Test platens were lubricated in order to reduce the radial frictional forces. The average crushing load $\left(P_{\mathrm{a}}\right)$ and SAE values were calculated using following relations:

$P_{\mathrm{a}}=\frac{\int P \mathrm{~d} \delta}{\delta}$

and

$\mathrm{SAE}=\frac{\int P \mathrm{~d} \delta}{m}$

where, $P, \delta$ and $m$ are the load, the displacement and the mass of the tube(s), respectively.

\section{Results and discussion}

\subsection{Compression behavior of Al foam filler}

Fig. 4 shows the compressive stress-strain curves of the prepared $\mathrm{Al}$ foams of three different densities: 0.27, 0.35 and $0.43 \mathrm{~g} \mathrm{~cm}^{-3}$. In order to show the repeatability of
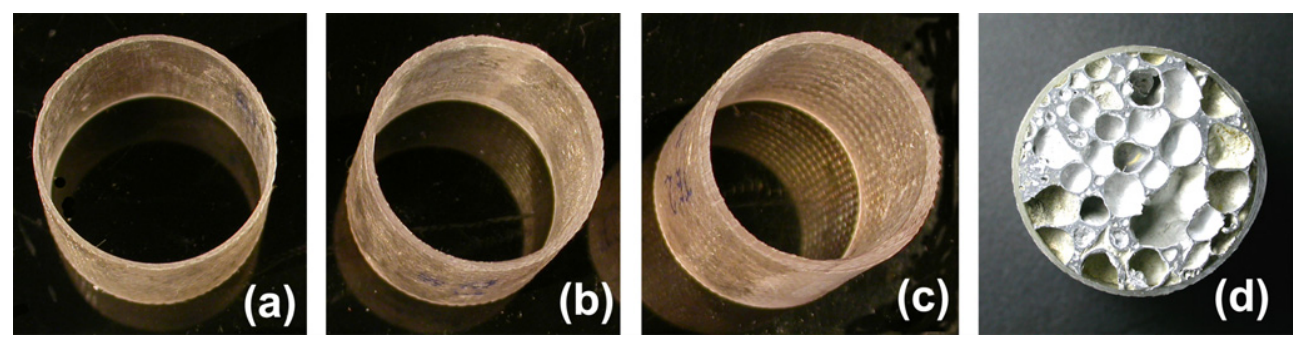

Fig. 2. Empty composite tubes: (a) 3-layer $0.57 \mathrm{~mm}$, (b) 5-layer $0.85 \mathrm{~mm}$ and (c) 7-layer $1.32 \mathrm{~mm}$ and (d) foam-filled $0.57 \mathrm{~mm}$ thick composite tube. 




Fig. 4. Stress-strain curves of Al foams of various densities.

compression stress-strain behavior, two tests results are shown in Fig. 4 for each foam density. It is also noted in Fig. 4 that the plateau stresses of foams are not constant and increase with increasing strain. It is supposed that foams having homogeneous cell size and cell size distribution show steady plateau stress in collapse region. But in reality, differences in cell size and cell distribution cause the collapse of weak cells before the collapse of strong cells. This leads to increase in the stress values in the collapse region.

\subsection{Compression behavior of the empty Al tube}

Typical load-displacement curve of empty Al tube is shown in Fig. 5. Empty Al tubes crushed in diamond mode. Totally 10 compression tests were conducted and average crushing loads corresponding to $50 \%$ deformation were determined. The average crushing loads varied between 0.93 and $1.08 \mathrm{kN}$ with a mean average crushing load of $0.99 \mathrm{kN}$. The total number of the folds formed was 7-8. The densification of empty tubes starts after $22 \mathrm{~mm}$ displacement, corresponding to about $80 \%$ of the initial tube length as seen in Fig. 5. The top view of a crushed empty



Fig. 5. Load vs. displacement behavior of empty Al tube deforming in diamond mode.
Al tube sample is shown in Fig. 6. The folds seen in this figure are eight-cornered. Although the first fold formation in empty tube was axisymmetric, the deformation proceeded with diamond mode; a similar deformation behavior was also previously observed in empty Al tubes and it was due to the influence of the axisymmetric trigger on the first fold [28].

\subsection{Compression behavior of empty composite tubes}

In the tested empty composite tubes two crushing modes are clearly distinguishable: (a) progressive crushing through external spraying and (b) catastrophic failure via compressive shear and/or axial splitting of the tube wall. These crushing modes are in accord with the crushing modes proposed previously by Ramakrishna and Hamada [15]. Among five tests only one $0.6 \mathrm{~mm}$ thick tube sample failed by catastrophic failure while one of three $1.30 \mathrm{~mm}$ thick composite tube sample failed by catastrophic failure.

The load-displacement curve of a $0.55 \mathrm{~mm}$ thick empty composite tube sample deforming in progressive crushing mode is shown in Fig. 7(a). The corresponding deformed structures of the tube at various displacements numbered in Fig. 7(a) are shown in Fig. 7(b). The tube deforms elastically until the peak-load (marked as 1 in Fig. 7(a)), thereafter localized deformation triggers near one of the ends of the tube (see 2 in Fig. 7(b)) and progresses through the length of the tube. It is known that progressive crushing mode can be achieved by chamfering one of the ends of the composite tube $[13,29]$. When the compressive load is applied, the load at the tip of the chamfer end of the tube increases significantly, leading to micro fracture initiating and the progression of the crushing zone. The observed progressive crushing mode triggering in the studied composite tubes is believed partly due to the imperfections at the tube end faces presumably introduced during the sectioning of the tubes with diamond saw. Delaminations introduced during the sectioning of the composite tubes

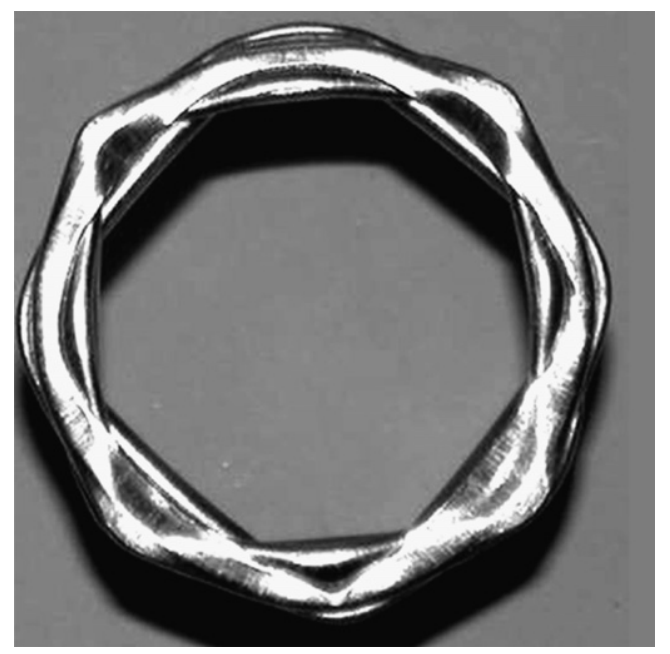

Fig. 6. View of a crushed empty Al tube in diamond mode. 

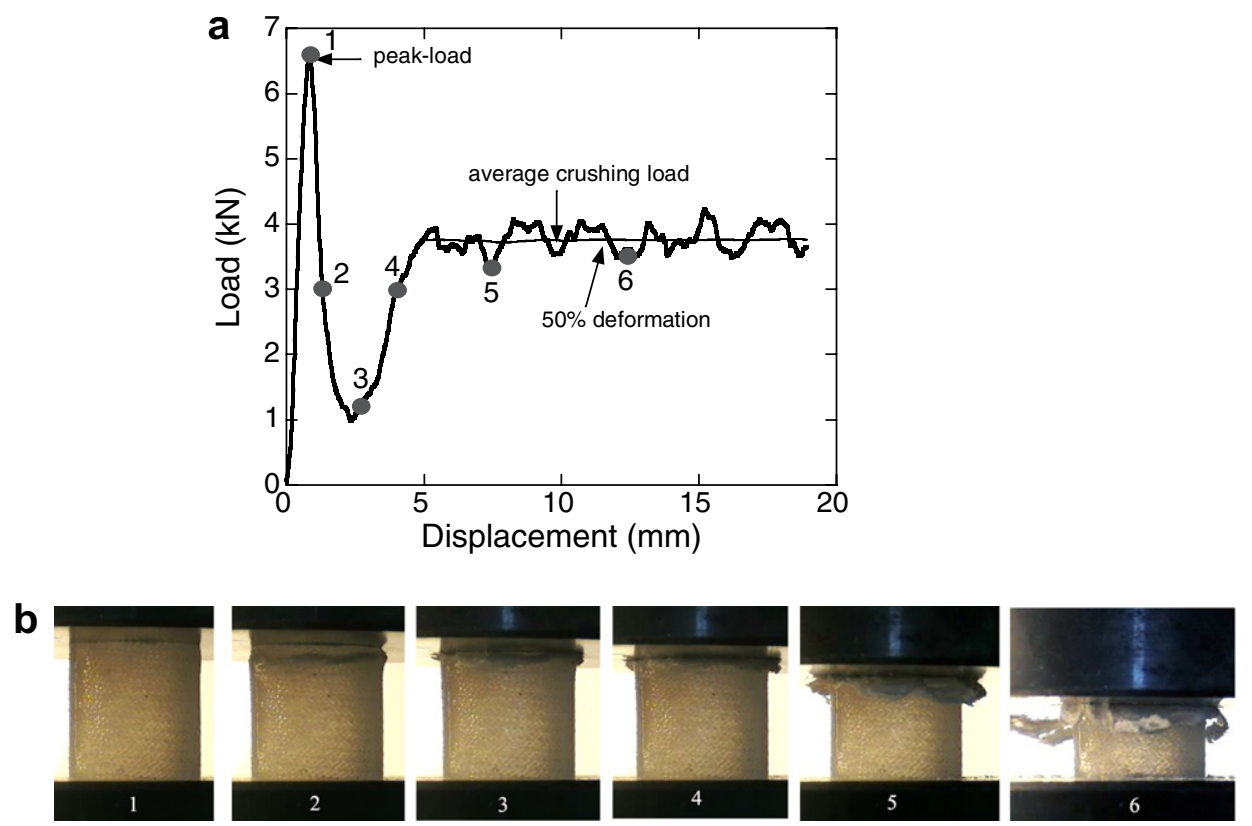

Fig. 7. (a) Load-displacement curve of an empty composite tube of $0.55 \mathrm{~mm}$ thick showing progressive crushing mode and (b) the corresponding deformation histories at various displacements numbered in (a).

are likely to trigger the deformation from one of the ends of the tube. The imperfect contact forces between the tube and compression test platen may also increase the load locally in the contact area, leading to the initiation and progression of the crushing zone from one of the ends of the tube. Following the initial peak-load due to the localization of the deformation in an area near one of the tube ends, the load decreases until the point 3 in Fig. 7(a). After this point deformation switches to progressive crushing mode and the load values increase to an average value (average crushing load) as shown in Fig. 7(a). Further deformation of the tube proceeds with outward splaying mode (4-6 in Fig. 7(b)). Similar deformation modes were also observed previously in a glass fiber/epoxy composite [16]. The mean average crushing loads of the tubes were calculated in the progressive crushing mode of the load-displacement curves, after point 4 of Fig. 7(a).

Figs. 8(a) and (b) show sequentially the load-displacement curve and deformation history of a composite tube sample failed by the catastrophic failure. The composite tube fails through the compressive shear regions, comprising two shear lines forming along the diagonal axes of the tube (Fig. 8(b)). Following the peak-load (1 in Fig. 8(a)), the load values decrease to a minimum (point 3); thereafter, the load values increase as two shear-cups are compressed together (3-5 in Fig. 8(b)). In addition to the compression shear, axial splitting was also observed in catastrophically failed composite tube samples.

The load-displacement curves of empty Al tube and composite tubes of different wall thicknesses failed by progressive crushing mode are shown in Fig. 9(a) for comparison. Both, the peak-load and average crushing load values of the composite tube, increase with increasing tube thick- ness as shown in Fig. 9(b), while the peak-load values show a stronger dependence to the tube wall thickness. Although the peak-load and crushing load values were found to increase with increasing tube thickness, SAE values did not change significantly within the studied tube wall thickness range.

\subsection{Compression behavior of the empty composite and empty hybrid tubes}

In order to estimate precisely the effect of hybrid tube construction on the crushing load and SAE values of the composite and $\mathrm{Al}$ tubes, thinner composite tubes $(t=0.53-0.72 \mathrm{~mm})$ were selected and used in hybrid tubes. Total 8 hybrid tubes were tested and similar to empty composite tubes, two crushing modes were observed; progressive (6 samples) and compression shear (2 samples). Fig. 10(a) and (b) show sequentially the typical load-displacement curve and deformation history, as function of displacement, of a composite hybrid tube sample failed by progressive crushing mode. Following the initial peakload due to the localization of the deformation in an area near one of the tube ends, the load decreases until point 3 in Fig. 10(a), a behavior very much similar to the crushing behavior of empty composite tube in the initial deformation region. In hybrid tubes it is also noted that metal tube folding triggers at the same place that composite tube deformation triggers for the progressive crushing. A relatively large detached composite piece marked with arrow in Fig. 10(b) is also seen. Similar to empty composite tube crushing behavior, after point 3 in Fig. 10(a) deformation mode switches to progressive crushing mode and load values reach a constant average crushing load. Further 

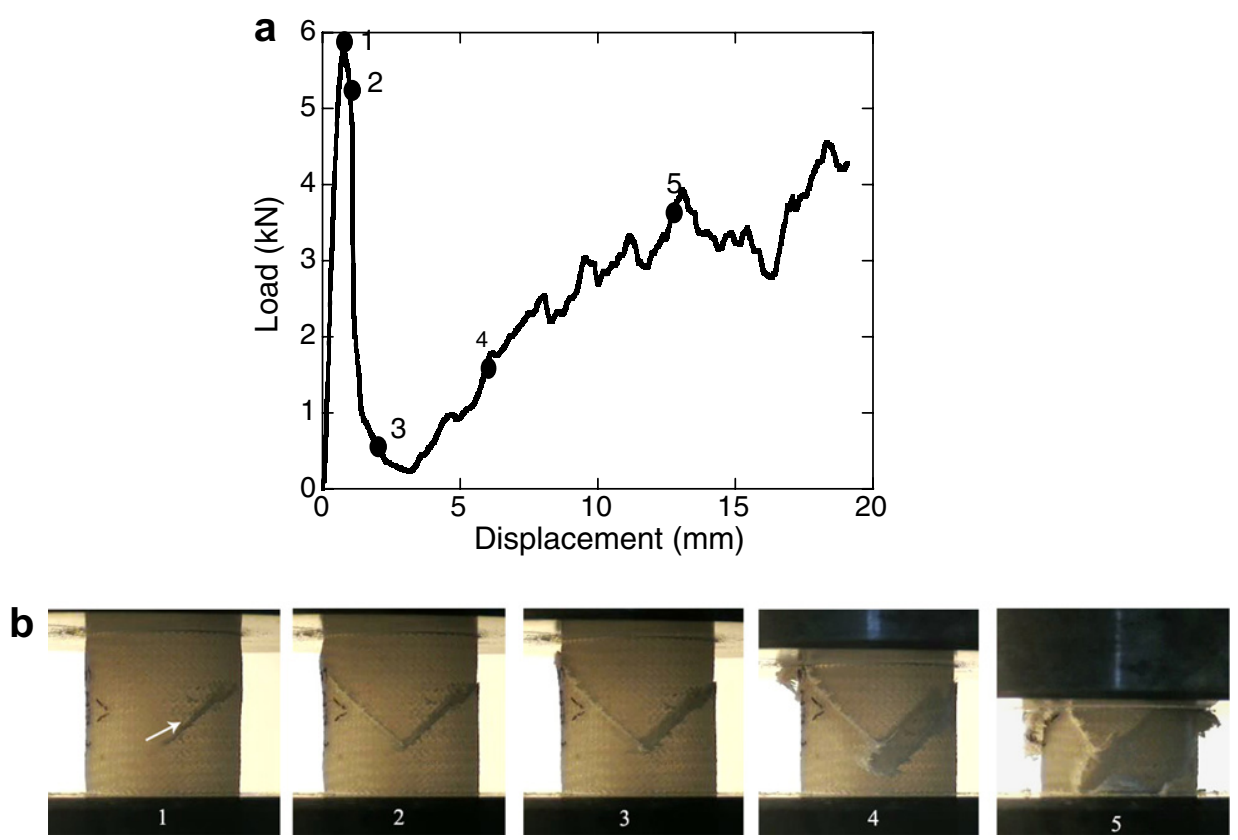

Fig. 8. Load-displacement curve of an empty composite tube of $0.59 \mathrm{~mm}$ thick showing catastrophic crushing mode and (b) the corresponding deformation histories at various displacements numbered in (a).
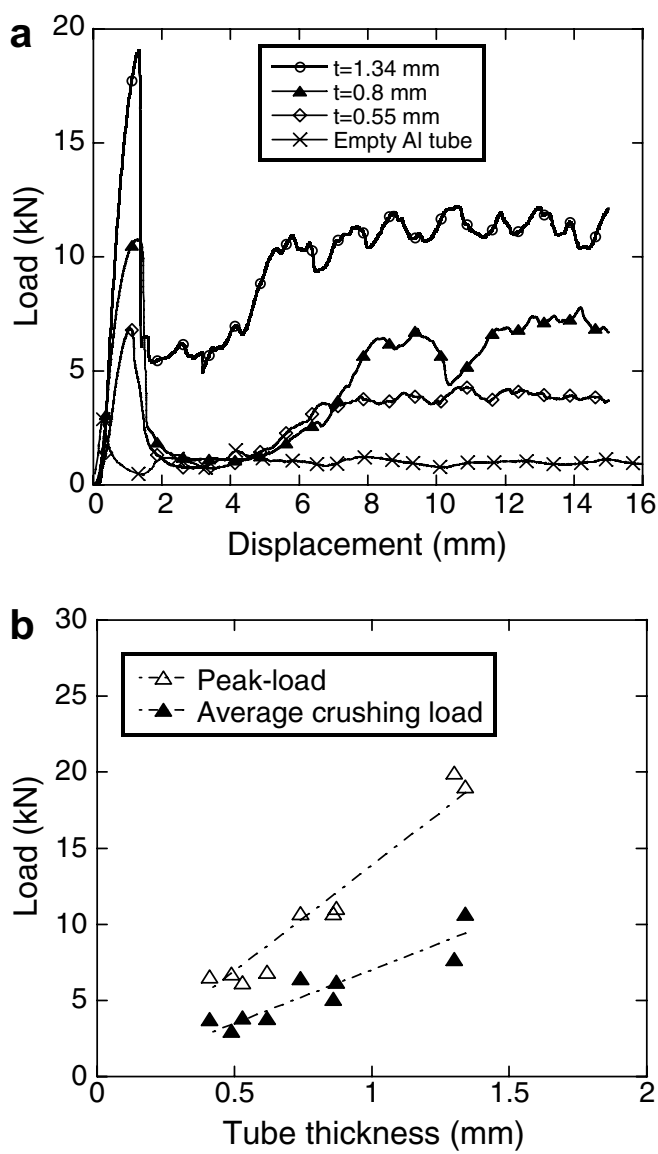

Fig. 9. (a) Typical load-displacement curves of tubes of three different wall thicknesses and (b) the effect of the tube thickness on the peak-loads and average crushing loads. deformation proceeds with outward splaying mode (Fig. 10(b)), similar to empty composite tubes. Fig. 11(a) and (b) show the typical load-displacement curve and deformation history, as function of displacement, of a hybrid tube sample failed by compression shear, respectively. In Fig. 11(b) the compression shear of the outer composite tube and the folding of the inner $\mathrm{Al}$ tube are marked with arrows. In these samples, the peak-loads and crushing loads are relatively lower than those of the samples failed by progressive crushing mode. The peakloads in catastrophically failed samples were 7.4 and $6.4 \mathrm{kN}$, while in progressively failed samples ranged between 9.1 and $11.2 \mathrm{kN}$. The mean average crushing loads of hybrid tubes decreased from $6.2 \mathrm{kN}(5.17-7.2 \mathrm{kN})$ in progressively failed samples to 3.15 and $3.2 \mathrm{kN}$ in catastrophically failed samples.

Since the crushing modes of composite tube of the hybrid tube and empty composite tube are very much similar, it may be concluded that the crushing behavior of hybrid tubes is dominated in a great extent by the composite tube crushing behavior. The deformation mode of $\mathrm{Al}$ tube is however changed significantly in hybrid tube. Fig. 12 shows the deformed shape of a hybrid tube in progressive crushing mode at $20 \mathrm{~mm}$ displacement, taken from the back of the crushing direction. Although the deformation mode of $\mathrm{Al}$ tube in hybrid tubes is similar to the diamond mode of empty tube, the shape and the geometry of the folds are not as homogeneous as the empty tube diamond mode. The change in the deformation mode of $\mathrm{Al}$ tube in hybrid tube is due to the prevention of the outer folding of $\mathrm{Al}$ tube. This is clearly seen in Fig. 12, where 



Fig. 10. (a) Load-displacement curve of an empty hybrid tube showing progressive crushing mode and (b) the corresponding deformation histories at various displacements numbered in (a).
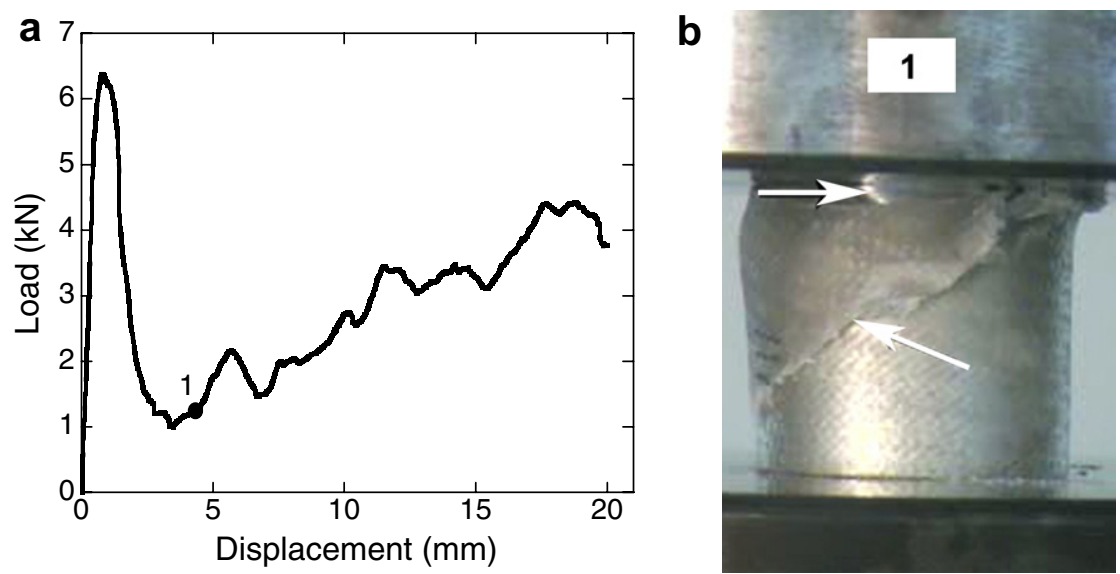

Fig. 11. (a) Load-displacement curve of an empty hybrid tube showing catastrophic crushing mode and (b) the corresponding view of the deformation at about $5 \mathrm{~mm}$ displacement.

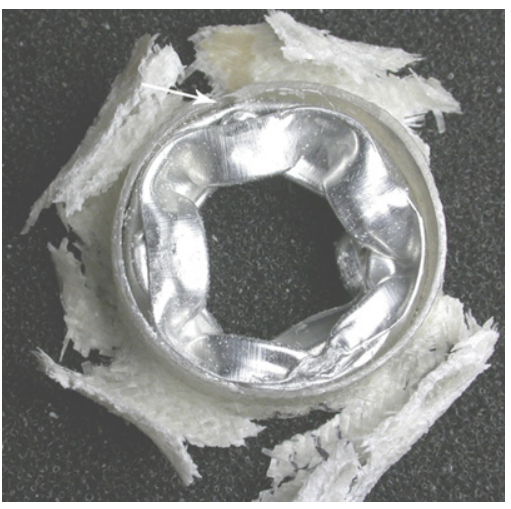

Fig. 12. A partially crushed hybrid tube deforming in progressive crushing mode.
Al tube folds are entirely through the inside. Although the empty tube shows an eight-cornered diamond mode of deformation, the number of corners increases in the hybrid tube. Since the composite tube wall in the samples failed by compression shear was partly effective in constraining $\mathrm{Al}$ tube, the diamond mode deformation in these samples was much more similar to that of empty Al tube except again the numbers of the folds increased in the hybrid tube particularly at the later stages of the deformation.

Fig. 13 shows the load-displacement curves of a hybrid tube deforming in progressive crushing mode, empty composite and $\mathrm{Al}$ tubes and the mathematical sum of the loads of the empty composite and empty Al tube. The higher load values of hybrid tube than those of empty composite 


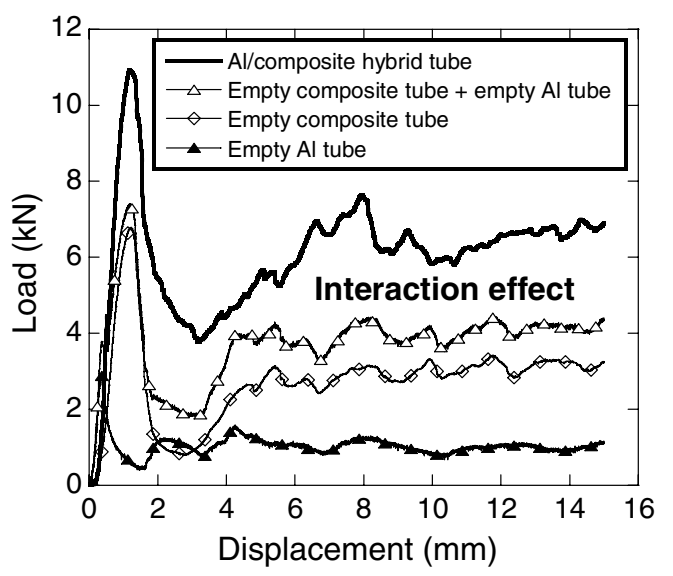

Fig. 13. Comparison of crushing loads of hybrid tubes with empty composite tube and empty $\mathrm{Al}$ tube and empty composite tube + empty $\mathrm{Al}$ tube.

tube + empty Al tube shown in this figure basically prove the interaction between $\mathrm{Al}$ and composite tube in hybrid tubes. The interaction, as stated previously, is a result of the constraint of the composite to the outward folding of Al tube.

\subsection{Compression behavior of the foam-filled composite and hybrid tubes}

The compression load-displacement curves of foamfilled composite tubes of increasing foam densities are shown in Fig. 14, together with the load-displacement curve of an empty composite tube. As the foam density increases, as clearly seen in this figure, peak-load and crushing load values increase. It is also noted in Fig. 14 that foam filling: (a) induces a continuously increasing load values following the peak-loads and (b) reduces the magnitude of load drop following the peak-load. The latter suggests that foam filling induces stable tube crushing triggering and progression. This was also supported by the observed lack of the compressive shear type failure in the tested 10 foam-filled composite tubes within the studied

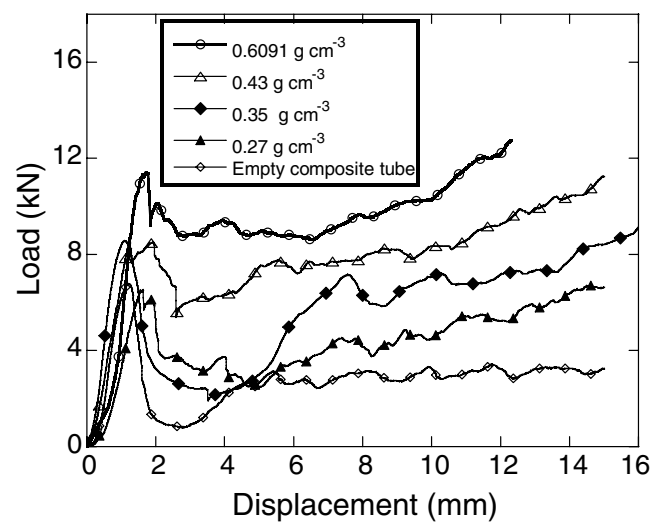

Fig. 14. Load-displacement curves of foam-filled and empty composite tubes. foam density range. The crushing load-displacement and crushing histories of a foam-filled composite tube are shown sequentially in Fig. 15(a) and (b). The crushing behavior is very similar to that of the progressively crushed empty tubes except the magnitude of the load drop following the peak-load decreases in the filled tube as noted previously. Although foam filling increases the crushing loads in the initial deformation region, it is ineffective in increasing the crushing loads of the composite tube in the progressive crushing region over those of foam + empty composite tube as shown in Fig. 16 for a $0.35 \mathrm{~g} \mathrm{~cm}^{-3}$ foam-filled composite tube. Once the tube crushing triggers from one of the ends of the tube, the bonding between foam and tube presumably separates or partially separates; therefore, the deformation of the tube and foam proceeds separately, leading to no interaction between tube and foam.

In foam-filled hybrid tubes, the folding of metal tube is constrained both by the foam filler and the outer composite tube. The resistance imposed by the filler and the composite was however found to be effective only in the initial stages of the deformation, since at the later stages of deformation the composite failed by axial cracks as shown in Fig 17(a). The crushing behavior of the composite tube shows in fact a mixture of progressive and catastrophic failure modes. In empty hybrid tubes, although metal tube crushes in inhomogeneous diamond mode, it deforms in concertina mode in the foam-filled hybrid tube as shown in Fig. 17 (b). The concertina folds in a foam-filled Al tube were previously shown to be uniform in shape and thickness and mostly outward of the filler [2]. While in hybrid tubes the folds are not as regular as in the case of foam-filled Al tube and tend to form through the inside of the foam. The irregular folds are most probably resulted from the entrance of the fractured composite pieces in between the folds. This also confirms that although composite tube fails by axial cracks it remains attached to $\mathrm{Al}$ tube and provides a partial confinement to $\mathrm{Al}$ tube folding. The load-displacement curves of foam-filled $\left(0.4 \mathrm{~g} \mathrm{~cm}^{-3}\right)$ hybrid tubes are shown in Fig. 18 together with load-displacement curves of empty composite and empty hybrid tubes. As shown in this figure foam-filled hybrid tubes show similar load values with those of empty hybrid tube, proving that the foam filling is not advantageous over the empty hybrid tubes. However, further experimentation on the thicker and lower density of foam filler may reveal specific tube and filler combinations, inducing progressive crushing mode of the composite tube.

\subsection{Specific absorbed energy}

The comparison of typical SAE values of the empty hybrid tubes with those of empty composite tube, empty Al tube and empty composite tube + empty Al tube is shown in Fig. 19(a). Since the energy absorption in the initial region of the deformation is predominantly affected by the triggering process only the load values of progressive crushing region were included in the calculations. The hybrid tube shows higher SAE values than those of empty 

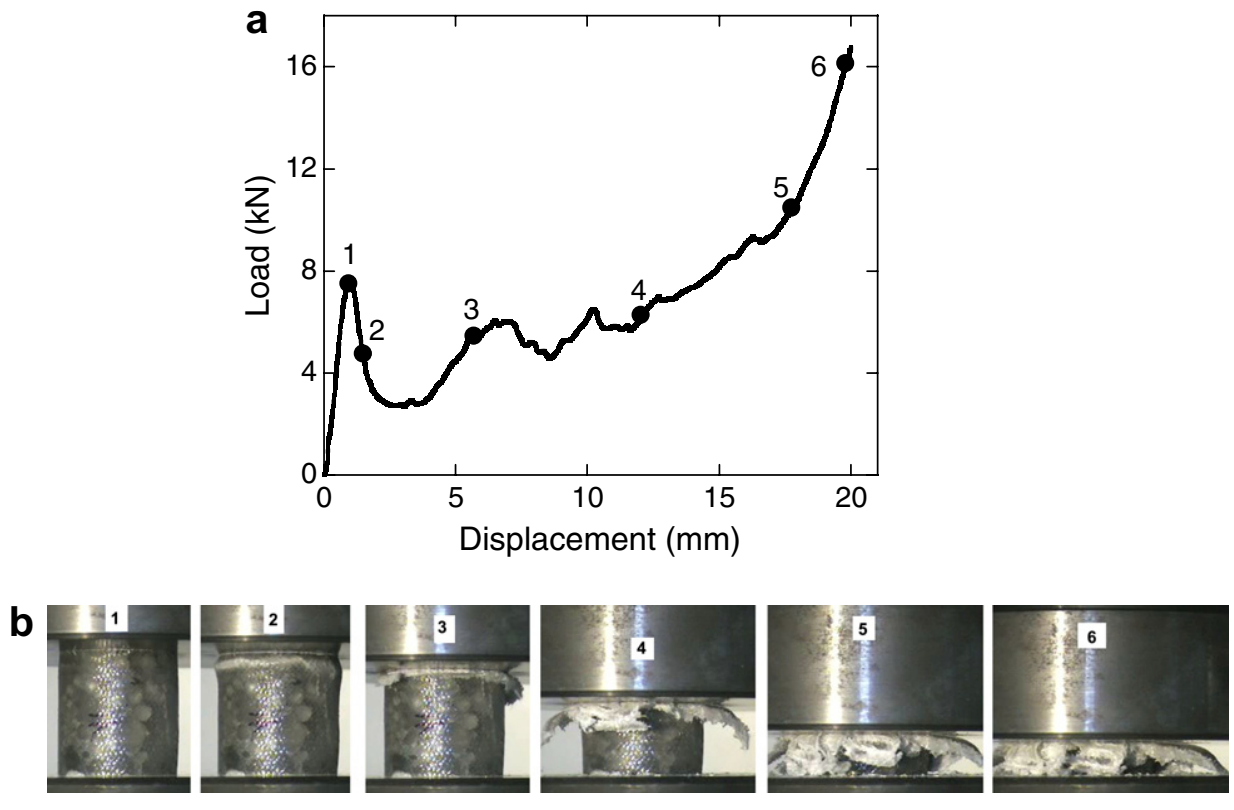

Fig. 15. (a) Load-displacement curve of a foam-filled $\left(0.35 \mathrm{~g} \mathrm{~cm}^{-3}\right)$ tube and (b) corresponding views of the deformation at various displacements numbered in (a).

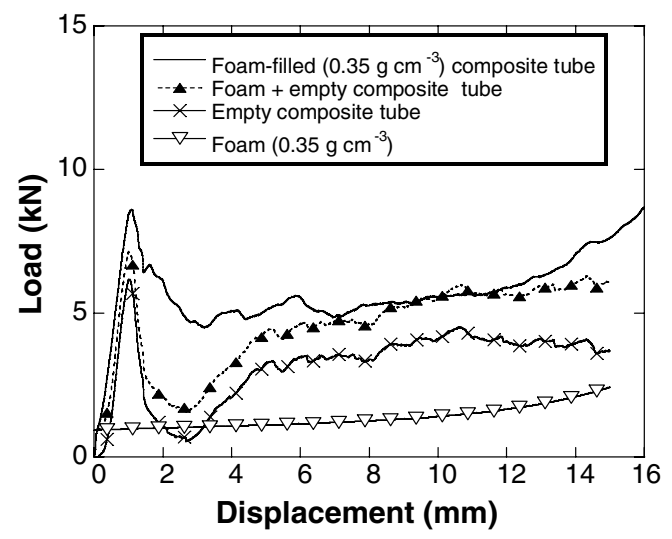

Fig. 16. Comparison of foam-filled composite tube crush loads with empty composite tube and $\mathrm{Al}$ foam and the sum of the loads of foam and empty composite tube.
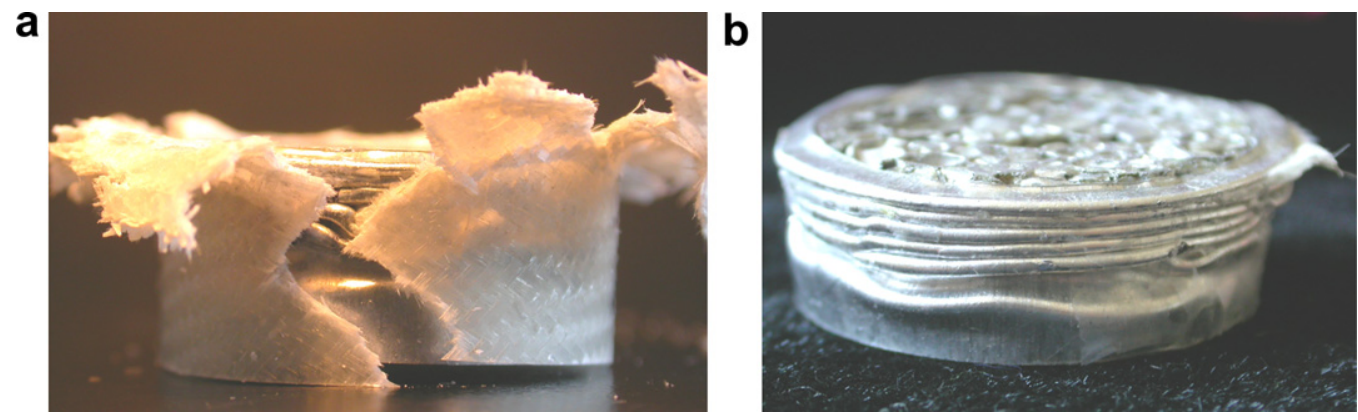

Fig. 17. Images of (a) a crushed foam-filled hybrid tube and (b) folding of Al tube in foam-filled hybrid tube.

composite tube + empty $\mathrm{Al}$ tube, showing, as in the case of load values, an interaction effect between composite tube and $\mathrm{Al}$ tube. A simple calculation based on the mean aver-

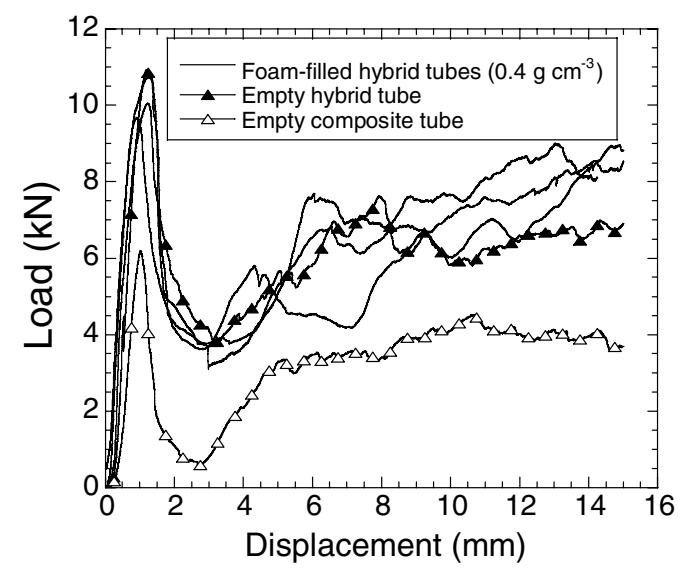

Fig. 18. Load-displacement curves of foam-filled hybrid, empty hybrid and composite tubes. 

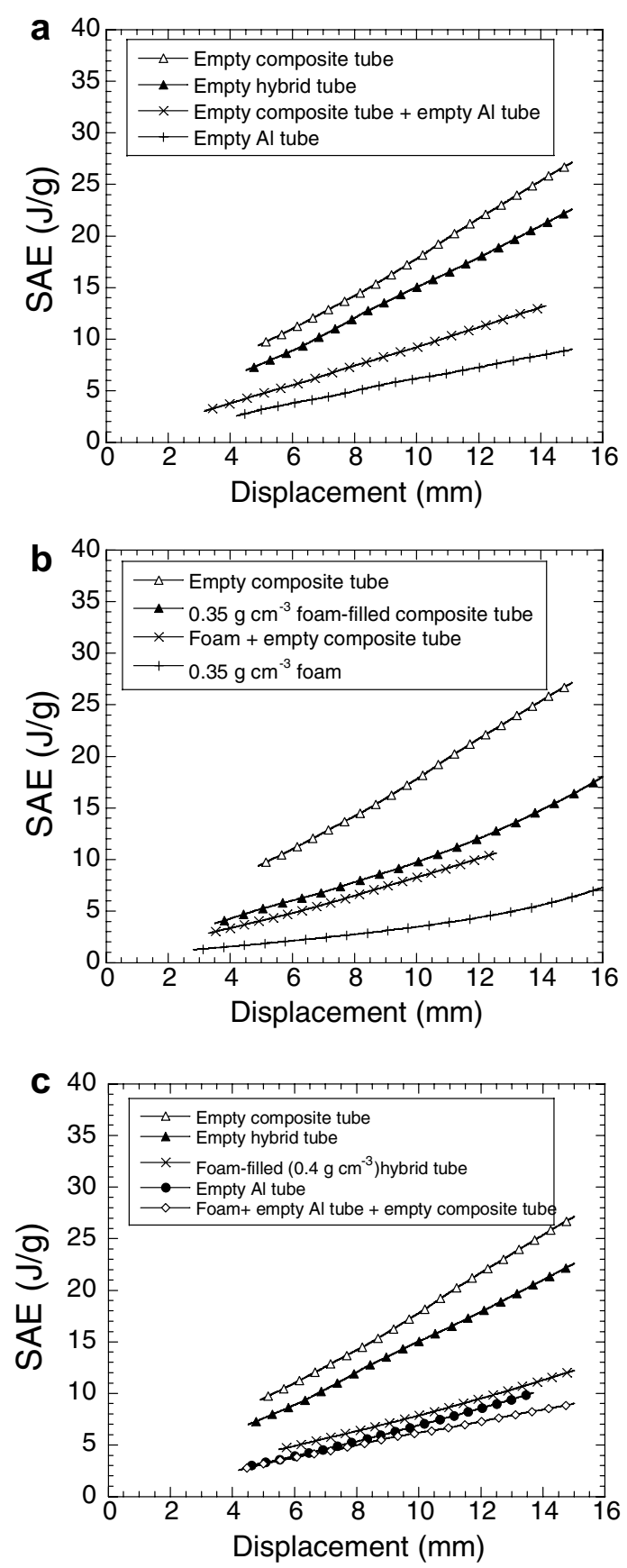

Fig. 19. Comparison of SAE values of (a) empty hybrid tube with empty composite, empty $\mathrm{Al}$ and composite $+\mathrm{Al}$ tubes, (b) foam-filled composite tube with empty composite tube, foam and empty composite tube + foam and (c) foam-filled hybrid tube with empty composite, hybrid and $\mathrm{Al}$ tubes, foam and foam + empty Al tube + empty composite tube.

mean average crushing load of empty Al tube. This value is also comparable with experimentally found strengthening coefficients of $\mathrm{Al}$ foam-filled $\mathrm{Al}$ tubes, ranging between 1.7 and 2.8; the higher value of strengthening arises from the use of adhesive between foam filler and tube [3]. In Fig. 19(b), typical SAE values of foam-filled composite, foam + empty composite tube and foam are shown together with SAE values of empty composite tube. As shown in Fig. 19(b), foam filling of composite tube gives similar SAE values with those of foam + empty composite tube, showing again no interaction between foam and tube. The foam filling of hybrid tubes results in SAE values similar to those of empty Al tubes, showing the ineffectiveness of foam filling in these tubes (Fig. 19(c)). However, foamfilled hybrid tubes show far less SAE values than empty composite and empty hybrid tubes.

\section{Conclusions}

An experimental study was conducted in order to determine the effect of foam filling on the quasi-static crushing behavior of an E-glass woven fabric composite and $\mathrm{Al}$ metal/composite hybrid tubes. Two crushing modes, progressive and catastrophic, were observed in the testing of empty composite and empty hybrid tubes. The progressive crushing mode resulted in higher crushing loads, hence higher SAEs. In empty hybrid tubes, the deformation mode of $\mathrm{Al}$ tube was found to be a more complex form of the diamond mode of deformation, leading to higher SAE values than the sum of the SAEs of empty composite tube and empty metal tube. The increased load and SAE values of hybrid tubes were attributed to the interaction between composite tube and $\mathrm{Al}$ tube. The foam filling of the composite tubes was found to be ineffective in increasing foam-filled tube crushing loads over the sum of the crushing loads of empty composite and foam in the progressive crushing region. However, the foam filling induced a more stable tube crushing trigger and progression. In the foamfilled hybrid tubes, the composite tube failed by axial splitting due the resistance imposed by the foam filler to the metal tube inward folding; therefore, foam filling was ineffective in increasing crushing loads; hence, SAE values over those of empty composite tube + empty $\mathrm{Al}$ tube + foam.

\section{Acknowledgement}

The authors would like to thank the Scientific and Technical Council of Turkey (TUBITAK) for the grant \#MISAG-227 and METALUM Company of Turkey for supplying $\mathrm{Al}$ tubes.

\section{References}

[1] Santosa S, Wierzbicki T. Crash behavior of box columns filled with aluminum honeycomb or foam. Comput Struct 1998;68:343-67.

[2] Kavi H, Toksoy AK, Guden M. Predicting energy absorption in a foam-filled thin-walled aluminum tube based on experimentally determined strengthening coefficient. Mater Des 2006;27:263-9.

[3] Toksoy AK, Tanoglu M, Guden M, Hall IW. The effect of adhesive on the strengthening of aluminum foam-filled circular tubes. J Mater Sci 2004;39:1503-6.

[4] Thornton PH. Energy absorptions by foam-filled structures. SAE Technical Paper Series 1980; 800372.

[5] Lampinen BH, Jeryan RA. Effectiveness of polyurethane foam in energy absorbing structures. SAE Technical Paper Series 1982; 820494.

[6] Reid SR, Reddy TY, Gray MD. Static and dynamic axial crushing of foam-filled sheet metal tubes. Int J Mech Sci 1986;28(5):295-322. 
[7] Reddy TY, Wall RJ. Axial compression of foam-filled thin-walled circular tubes. Int J Impact Eng 1988;7(2):151-66.

[8] Seitzberger M, Rammerstorfer FG, Gradinger R, Degischer HP, Blaimschein M, Walch C. Experimental studies on the quasi-static axial crushing of steel columns filled with aluminum foam. Int $\mathbf{J}$ Solids Struct 2000;37:4125-47.

[9] Santosa SP, Wierzbicki T, Hanssen AG, Langseth M. Experimental and numerical studies of foam-filled sections. Int $\mathbf{J}$ Impact Eng 2000;24:509-34.

[10] Hanssen AG, Langseth M, Hopperstad OS. Static and dynamic crushing of square aluminium extrusions with aluminum foam filler. Int J Impact Eng 2000;24(4):347-83.

[11] Guillow SR, Lu G, Grzebieta RH. Quasi-static axial compression of thin-walled circular aluminum tubes. Int J Mech Sci 2001;43: 2103-23.

[12] Singace AA. Collapse behaviour of plastic tubes filled with wood sawdust. Thin-Walled Struct 2000;37:163-87.

[13] Ramakrishna S. Microstructural design of composite materials for crashworthy structural applications. Mater Des 1997;18(3):167-73.

[14] Harte AM, Fleck NA. Deformation and failure mechanisms of braided composite tubes in compression and torsion. Acta Mater 2000;48(6):1259-71.

[15] Hamada H, Ramakrishna S. Energy absorption characteristics of crash worthy structural composite materials. Eng Mater 1998;141143:585-620.

[16] Saito H, Inai R, Yokoyama A, Hamada H. Basic study of progressive crushing mechanism. Eng Mater 2000;177-180:321-6.

[17] Chiu CH, Tsai K, Huang WJ. Effects of braiding parameters of energy absorption capability of triaxially braided tubes. J Compos Mater 1998;32:1964-83.

[18] Turner TA, Warrior NA, Robitaille F, Rudd CD. The influence of processing variables on the energy absorption of composite tubes. Composites Part A: Appl Sci Manufact 2005;36:1291-9.
[19] Warrior NA, Turner TA, Robitaille F, Rudd CD. The effect of interlaminar toughening strategies on the energy absorption of composite tubes. Composites Part A: Appl Sci Manufact 2004;35:431-7.

[20] Warrior NA, Turner TA, Robitaille F, Rudd CD. Effect of resin properties and processing parameters on crash energy absorbing composite structures made by RTM. Composites Part A: Appl Sci Manufact 2003;34:543-50.

[21] Zeng T, Fang D, Lu T. Dynamic crashing and impact energy absorption of 3D braided composite tubes. Mater Lett 2005;59:1491-6.

[22] Shin KC, Lee JJ, Kim KH, Song MC, Huh JS. Axial crush and bending collapse of an aluminum/GFRP hybrid square tube and its energy absorption capability. Compos Struct 2002;57:279-87.

[23] Harte AM, Fleck NA, Ashby MF. Energy absorption of foam-filled circular tubes with braided composite walls. Eur J Mech A/Solids 2000;19:31-50

[24] Babbage JM, Mallick PK. Static axial crush performance of unfilled and foam-filled aluminum-composite hybrid tubes. Compos Struct 2005;70:177-84.

[25] Schrade BH. US Patent No. 5151246, 1992.

[26] Guden M, Yuksel S. Compression behavior of SiC-particulate foams produced by foaming from powder compacts. J Mater Sci 2006;41: 4075-84.

[27] Toksoy AK, Güden M. The strengthening effect of polystyrene foam filling in aluminum thin-walled cylindrical tubes. Thin-Walled Struct 2005;43:333-50.

[28] Hanssen AG, Langseth M, Hopperstad OS. Static and dynamic crushing of circular aluminium extrusions with aluminium foam filler. Int J Impact Eng 2000;24:475-507.

[29] Jimenez MA, Miravete A, Larrode E, Revuelta D. Effect of trigger geometry on energy absorption in composite profiles. Compos Struct 2000;48:107-11. 